\title{
Reforma agrária: uma nota sobre o local de negociação
}

\author{
GUILHERME LEITE DA SILVA DIAS
}

$\mathrm{E}$ STA NOTA TEM UM OBJETIVO restrito, e não abrangente, como tende a ser a maioria dos documentos sobre reforma agrária. A questão a ser tratada gira em torno do local onde se pretende manter a negociação entre os atores sociais que são parte do conflito e de sua solução.

O desajuste entre as responsabilidades legais, a capacidade de ação e a responsabilidade política ficou evidente em dois incidentes que receberam maior atenção da mídia devido a sua gravidade. Em Corumbiara (Estado de Rondônia) e em Eldorado do Carajás (Estado do Pará), a polícia militar estadual cumpria, de modo questionável devido ao trágico resultado, determinação da justiça estadual para expulsar invasores de grandes propriedades rurais. A responsabilidade pelos crimes cometidos ainda pôde ser apurada, mas a responsabilidade política foi atribuída, sem qualquer exceção, ao governo federal. Conflitos abertos ficam sob a responsabilidade dos poderes locais, mas as tensões sociais latentes não são intermediadas pelos poderes locais e nem pelas representações políticas dos grupos envolvidos. Todos se voltam para o governo central e esperam que por meio dos serviços de uma burocracia gigante (com um regimento administrativo também excessivamente centralizado) o assunto seja resolvido de acordo com o interesse de cada uma das partes em conflito.

Para um melhor entendimento da questão proposta, é recomendável conhecer um pouco da história em torno da matéria. Desde nossa primeira Constituição republicana existe uma divisão de papéis entre o governo central - que deve conduzir a política fundiária no sentido de sua normatização e coordenação - e o governo estadual - que ficou com a incumbência de distribuir (ou vender) as terras não ocupadas. Esta era a variável estratégica mais importante, pois existia muita terra e pouca mão-de-obra para sua exploração. Estas terras são conhecidas tecnicamente como devolutas, conceito que revela um sentido muito importante do juízo de valor predominante na formação de nossa estrutura fundiária.

A definição jurídica de uma terra como devoluta implica um processo no qual o Estado, por meio de seu executivo, tem de provar diante do sistema judiciário que a terra não está ocupada. Neste processo, sinais de ocupação bastam para identificar o domínio da terra por alguma pessoa física que, portanto, pode reclamar sua propriedade (Dias, 1978). O princípio básico favorecido por essa determinação é o do direito de ocupação das terras da nação, como na época inicial da colonização por- 
tuguesa. Não se estabelece limite para este direito de ocupação das terras pelo indivíduo, mas o Estado está limitado na sua capacidade de intervir porque precisa provar diante da Justiça que não existem sinais de ocupação.

Nesse contexto, as autoridades estaduais e os juízes das comarcas são atores principais do processo. Os primeiros, porque podem decidir sobre a forma de vender as terras devolutas, e resolver qualquer conflito sobre a posse de um lote oferecendo a uma das partes envolvidas no conflito um lote alternativo às terras devolutas. Os segundos, porque têm o poder de reconhecer os sinais de ocupação que garantiriam o domínio privado sobre as terras. Nossa concentração fundiária é fruto desse processo histórico. Os conflitos eram resolvidos ao nível das autoridades locais e, aparentemente, nos dois episódios mais marcantes em que a autoridade central foi chamada a intervir utilizando forças militares para conter movimentos sociais Canudos e Contestado -, o que estava em jogo era muito mais a autonomia do movimento do que a questão da terra. A ordem foi sempre estabelecida pelos poderes locais dentro desse sistema de ocupação.

A exclusão social, no sentido de limitar o acesso à terra para os ex-escravos e os pobres, é a característica básica do processo que se seguiu dentro desse marco institucional. O que houve de diferente ocorreu no sul do país, onde o poder estadual favoreceu a concessão de terras para empresas de colonização. Nessas regiões, onde a pequena produção de colonos europeus teve um papel mais destacado no processo de desenvolvimento, o Movimento dos Trabalhadores Rurais Sem Terra (MST) conseguiu se organizar e crescer. A tradição nessas áreas é diferente porque sempre se reconheceu um espaço para esse grupo autônomo de atores sociais, representados inicialmente pelas empresas de colonização e depois pelas suas cooperativas agrícolas de produção.

Uma das conseqüências desse processo é que a autoridade dos poderes executivo e judiciário locais se reduz bastante quando se esgotam as reservas de terras devolutas com aptidão agrícola. A partir deste ponto é a desapropriação de terras que pode resolver futuros problemas ou a emigração dos excluídos. Resta uma outra característica importante, decorrente da provável concentração excessiva das terras: a forte suspeição dos excluídos em relação às autoridades locais.

O esgotamento da fronteira agrícola já é uma realidade nos anos 50 nas regiões Nordeste, Sudeste e Sul. O processo vai se completar nos anos 70 na região Centro-Oeste e nos limites da região amazônica. Os primeiros movimentos organizados em favor da reforma agrária surgem nesse contexto de esgotamento da fronteira agrícola nos Estados de Pernambuco, Rio de Janeiro e Rio Grande do Sul; nos outros Estados onde a atividade agrícola era importante, a emigração para as novas fronteiras ainda existentes funcionava como válvula de escape, assim como a migração para as cidades.

Como o poder normativo estava no Congresso e o poder executivo central era visto pelas forças de esquerda como a forma de conduzir um processo de revolução social de cima para baixo, a luta política pela reforma agrária convergiu para 
concentrar no executivo federal o poder de desapropriar terras para esta finalidade, assim como de conduzir o processo de assentamento.

Os militares, na revolução de 64 , também viram na centralização do poder na esfera federal razões de lógica de segurança nacional (no contexto da guerra fria) e uma estratégia de desenvolvimento econômico (concentração e aumento de poupança doméstica), consolidando o governo federal como principal ator e interlocutor do processo de reforma agrária. Grandes donos de terras e grandes grupos econômicos viam nessa centralização um elemento de defesa de seus interesses no que dizia respeito ao poder do Congresso, em especial do Senado, uma forma de normatizar o poder executivo e uma segurança no processo político, porque o diálogo era com um único interlocutor, o governo federal por meio da burocracia do Incra.

A colonização da fronteira pré-amazônica é vista como uma solução, mesmo que parcial, para o problema da exclusão social. O governo federal cria mecanismos de incentivo fiscal, financiamentos e aloca volumes razoáveis de recursos fiscais para a colonização privada e pública até o início dos anos 80 , quando o processo de liberalização política já estava a meio curso. Entre as duas grandes secas no Nordeste, de 81 e 83, movimentos sociais sob a liderança da Igreja Católica começam a levantar a questão de que a migração forçada para as fronteiras agrícolas era um paliativo inaceitável, porque a falta de enfrentamento da exclusão social nas regiões de origem era o caminho para sua reprodução, com o devido tempo, na nova fronteira.

Esse é o cenário dominante em que nasceu o MST, nos Estados do sul do país. É em meio a um processo de redemocratização e afirmação dos direitos de cidadania, por meio de uma nova Constituição que consolidou um forte processo de descentralização administrativa e política, fortalecendo governos municipais até mais do que os estaduais. Esta mesma Constituição, no entanto, depois de um de seus episódios mais árduos e longos de debate, manteve o direito de expropriação de terra para fins de reforma agrária exclusivamente no governo federal. Repetiu-se o mesmo quadro político: conservadores confiantes na sua representação mais forte no Congresso, em especial no Senado, com poderes de neutralizar qualquer ação mais independente do executivo federal. E as esquerdas ainda acreditavam que qualquer ação revolucionária em favor da reforma agrária viria do governo central apoiado por forças populares (Ribeiro, 1987).

A estratégia desenvolvida pelo MST, predominantemente nos Estados do Sul (mais recentemente em São Paulo e no Mato Grosso do Sul), foi bem sucedida, por duas razões principais. A primeira porque a maioria das invasões deu-se em terras que eram efetivamente improdutivas no sentido da lei, de forma que a desapropriação foi possível naquele mesmo local ou em local próximo a ele por conveniência. A segunda decorre de um circuito virtuoso em que a arregimentação de grupos representativos dos excluídos do campo, a sua organização para promover inúmeras invasões e o posterior assentamento de milhares de famílias (financiados principal- 
mente pelo próprio Incra, que era, assim, conduzido, e não o condutor do processo) eram partes de um processo de reafirmação do movimento social que se demonstrava capaz de fazer o que a autoridade pública não havia feito (Navarro, 1997).

As transformações no sistema produtivo agrícola são, no entanto, muito grandes, fazendo com que os excluídos sejam não apenas aqueles que não tiveram qualquer oportunidade como também aqueles produtores com pequenas áreas, próprias ou arrendadas, que viram sua renda diminuir, comprometendo sua permanência e de sua família na atividade. Esse processo decorre apenas em parte da abertura do mercado para uma maior concorrência externa. Outro fator, talvez mais importante, é a restruturação do sistema de abastecimento urbano, exigindo escala, qualidade e homogeneidade do produto. Essa nova dinâmica competitiva doméstica transforma um pequeno produtor, com tecnologia e acesso a capital, em fator determinante do desemprego de outro produtor menos competitivo. As integrações de frango e de suínos no sul do país vivem esse processo de modo intenso, assim como os fornecedores de leite para as cooperativas centrais regionais.

O caso brasileiro não foi muito diferente daquele de outros países mais desenvolvidos, onde a pequena produção também sofreu esse tipo de pressão competitiva. Uma política agrícola diferenciada pode reduzir o custo social dessa transformação e, principalmente, criar condições mais flexíveis no mercado de trabalho, gerando empregos de tempo parcial ou sazonais para acomodar as gerações novas com as mais velhas na mesma região. Esse entendimento da necessidade de uma articulação entre o urbano e o rural é o traço fundamental da diferença entre a nossa experiência radical de desigualdade social com caminhos mais equilibrados verificados na Ásia (Japão, Coréia do Sul e China) e na Europa Ocidental depois dos grandes surtos de emigração na última passagem de século. A boa execução dessas políticas diferenciadas exige a maior participação das lideranças políticas locais; seu custo e benefício só é corretamente avaliado pela população local, cujo apoio garante sua continuidade e, principalmente, o desenvolvimento de critérios de seleção entre os participantes.

A tradição centralizadora dos movimentos pela reforma agrária foi implicitamente endossada pelos organizadores da marcha dos sem-terra na capital do país, reafirmando o marco legal vigente que reconhece no Congresso Federal e na burocracia central os únicos interlocutores válidos. Qualquer outra forma de representação política foi recusada quando a coordenação do movimento rejeitou uma proposta de negociação por meio de uma comissão de representação bastante ampla e flexível. A reforma agrária é um dos instrumentos de uma política diferenciada e, exceto em um contexto revolucionário, deve envolver necessariamente uma negociação entre donos de terra, produtores agrícolas excluídos e a autoridade pública que vai garantir o cumprimento do acordo.

O processo de democratização do país move-se na direção da descentralização de todos os serviços públicos, o que dá cada vez menos legitimidade ao burocrata do governo federal nas negociações e nas ações de reforma agrária. Em uma confi- 
guração alternativa, em que os atores da negociação fossem, de pleno direito, as autoridades estaduais e municipais, a representação dos donos de terras da região e os movimentos sociais organizados regionalmente, o desenvolvimento do processo seria muito mais eficiente. O papel do governo central é o de prover os meios de compensação entre regiões com mais ou menos terras e trabalhadores rurais buscando uma forma digna de sobrevivência.

\section{Bibliografia}

DIAS, Guilherme L. S. Estrutura agrária e crescimento extensivo. Tese de livre-docência, São Paulo, FEA/USP, 1978, cap.3; não publicada.

RIBEIRO, Ivan O. Agricultura, democracia e socialismo (org. Carlos N. Coutinho e M. Beatriz de A. David). Rio de Janeiro, Paz e Terra, 1987, caps. 7 e 8.

NAVARRO, Zander. Sete teses equivocadas sobre as lutas sociais no campo, o MST e a reforma agrária. Porto Alegre, Departamento de Sociologia da UFRGS, 1997 (mimeo.).

Guilherme Leite da Silva Diasé professor titular da Faculdade de Economia e Administração da USP. 